\title{
Alterações Morfoanatômicas Foliares da CANa-de-AçúCAR NA Fase de Estabelecimento em Condições de Matocompetição ${ }^{1}$
}

\author{
Morph Anatomical Changes of Sugar Cane Leaves in Phase of Establishment Under Weed \\ Competition
}

FIGUEIREDO, P.A.M. ${ }^{2}$, RAMOS, S.B. ${ }^{2}$, VIANA, R.S. ${ }^{3}$, LISBOA, L.A.M. ${ }^{4}$ e HEINRICHS, R. ${ }^{3}$

\begin{abstract}
RESUMO - Com o objetivo de avaliar parâmetros de produção e possiveis alterações morfoanatômicas de tecidos foliares da cana-de-açúcar, variedade RB 867515 , na fase de estabelecimento, em condições de matocompetição, foi conduzido um experimento em vasos em Dracena, Estado de São Paulo, entre os meses de abril e junho de 2010, na Universidade Estadual Paulista Júlio de Mesquita Filho. Foram utilizadas as espécies Brachiaria brizantha e Brachiaria decumbens, consideradas como invasoras. Foi utilizado o delineamento inteiramente casualizado, sendo sete tratamentos e cinco repetições, totalizando 35 parcelas ou vasos. Os tratamentos variaram de acordo com o número de sementes de Brachiaria brizantha e Brachiaria decumbens, sendo: T1 - ausência de matocompetição; T2 - baixa ocorrência de matocompetição com Brachiaria brizantha; T3 - média ocorrência de matocompetição com Brachiaria brizantha; T4 - alta ocorrência de matocompetição com Brachiaria brizantha; T5 baixa ocorrência de matocompetição com Brachiaria decumbens; T6 - média ocorrência de matocompetição com Brachiaria decumbens; e T7 - alta ocorrência de matocompetição com Brachiaria decumbens. Após 60 dias do plantio da cana-de-açúcar e das espécies invasoras, foram avaliados: peso da matéria seca total das plantas; espessura da epiderme da face superior ou adaxial; espessura da epiderme da face inferior ou abaxial; espessura do mesofilo; espessura do limbo; diâmetro dos vasos xilemáticos; e diâmetro dos vasos floemáticos. A matocompetição das espécies Brachiaria brizantha e Brachiaria decumbens, consideradas como invasoras, provocou redução das características morfoanatômicas e de produção da cana-deaçúcar. De maneira geral, Brachiaria decumbens foi a espécie que mais influenciou negativamente a espessura foliar da cana-de-açúcar.
\end{abstract}

Palavras-chave: morfologia, tecidos, Brachiaria brizantha, Brachiaria decumbens, Saccharum spp.

\begin{abstract}
Aiming at the assessment of the production parameters and leaftissues morph anatomical possible changes of the sugar cane RB 867515 variety in its establishment phase in the conditions of weed competition, a study over vases has been accomplished in the city of Dracena, São Paulo State, from April to June, 2010, at Universidade Estadual Paulista "Júlio de Mesquita Filho". The species Brachiaria brizantha e Brachiaria decumbens, which are regarded as invaders, were used. It was also used the Completely Randomized Design with seven treatments and five repetitions, totalizing 35 lots or vases. The treatments ranged according to the number of Brachiaria brizantha and Brachiaria decumbens seeds, as it follows: T1 - no occurrence of weed competition; T2 - low occurrence of weed competition with Brachiaria brizantha; T3 - medium occurrence of weed competition with Brachiaria brizantha; T4 - high occurrence of weed competition with Brachiaria brizantha; T5 - low occurrence of weed competition with Brachiaria decumbens; T6 - medium occurrence of weed competition with Brachiaria decumbens, and T7 - high occurrence of weed competition with Brachiaria decumbens. There was an evaluation
\end{abstract}

Recebido para publicação em 27.9.2012 e aprovado em 5.3.2013.

2 Universidade Estadual Paulista “Júlio de Mesquita Filho” - UNESP, Campus de Dracena, SP, Brasil, <paulofigueiredo@dracena.unesp.br>; ${ }^{3}$ Faculdade de Tecnologia de Araçatuba-FATEC ; ${ }^{4}$ UNESP, Campus Dracena e Ilha Solteira, SP, Brasil.

Planta Daninha, Viçosa-MG, v. 31, n. 4, p. 777-784, 2013 
over the following issues after 60 days of the sugar cane plantation and the invading plants: the weight of the total dry matter of the plants, the thickness of the upper surface epidermis or adaxial, the thickness of the lower surface or abaxial, the thickness of the mesophill, the thickness of the limbo, the diameter of the xylematic vessels and the diameter of the phloem vessels. The weed competition of the species Brachiaria brizantha e Brachiaria decumbens, which are considered as invaders, provoked some reduction of the morph anatomical characteristics and of the sugar cane production. In general, the Brachiaria decumbens was the species which mostly influenced the leaf thickness of the sugar cane in negative aspects.

Keywords: morphology, tissues, Brachiaria brizantha and Brachiaria decumbens, Saccharum spp.

\section{INTRODUÇÃO}

O Brasil possui uma área de aproximadamente 10,7 milhões de hectares ocupados com a cultura da cana-de-açúcar, com produtividade média estimada de $76,8 \mathrm{t} \mathrm{ha}^{-1}$ para a safra 2011/12 (IBGE, 2011). O incremento esperado na produção de colmos de cana-de-açúcar para atingir essas metas deverá ocorrer, entre outros, também por meio do aumento da produtividade agroindustrial. O crescimento do setor sucroenergético brasileiro é de fundamental importância como estratégia de suprir o mercado nacional e internacional, fornecendo combustivel renovável e diminuindo a pressão para extração de combustiveis de origem fóssil.

Entre os fatores bióticos, as plantas daninhas são um dos principais componentes do agroecossistema da cana-de-açúcar que interferem no desenvolvimento e na produtividade dessa cultura. A presença dessas plantas pode interferir no processo produtivo da cana-deaçúcar, competindo pelos recursos do meio, principalmente água, luz e nutrientes, liberando substâncias alelopáticas, atuando como hospedeiro de pragas e doenças comuns à cultura e interferindo nas práticas de colheita (Pitelli, 1985).

Segundo Blanco (1972), o grau de competição na associação mato-cultura depende da intervenção de fatores ligados à comunidade infestante, que envolvem composição específica, distribuição, cultura, espécie, espaçamento, densidade, época e duração do período de convívio entre culturas. Também depende das condições edáficas e climáticas e dos tratos culturais.

A ocorrência de um ou mais desses componentes de interferência poderá reduzir a quantidade de colmos colhidos e diminuir o número de cortes economicamente viáveis (Lorenzi, 1988).

Um dos fatores que afetam negativamente a produtividade dos canaviais é a presença de plantas daninhas nas áreas de cultivo, pois estas competem pelos fatores do meio, principalmente por água, espaço, nutrientes e luminosidade, causando sérios danos à cultura da cana-de-açúcar. Estudos acerca da competição de plantas invasoras em lavouras de interesse econômico são de grande importância no contexto agronômico, uma vez que simulam uma situação real de campo em diversos níveis de infestação (Harper, 1977). Segundo Lorenzi (1988), as plantas daninhas comprometem o desenvolvimento vegetativo das outras plantas, ocasionam redução na quantidade de colmos e provocam diminuição do número de cortes economicamente viáveis. Além disso, no momento da colheita, dificultam o corte mecanizado e comprometem o rendimento das máquinas e a qualidade final do produto (Correia \& Kronka, 2010). De acordo com Kuva et al. (2003), a ausência de controle durante todo o ciclo da cana-de-açúcar, ou seja, da emergência da cultura ao corte, resultou em $40 \%$ de redução da produtividade, quando comparado ao obtido na ausência total de plantas daninhas.

A sintomatologia é muito utilizada para avaliação dos danos causados por fatores bióticos ou abióticos. Nesse caso, aspectos estruturais auxiliam na compreensão dos mecanismos que provocam as injúrias (Sant'anna-Santos et al., 2007).

No entanto, é importante salientar que as alterações visíveis a olho nu são, na verdade, derivadas de modificações das estruturas dos 
tecidos dérmicos, fundamentais ou vasculares das plantas, tornando-se necessário o conhecimento aprofundado dessas transformações motivadas pelas variações do meio (Castro et al., 2009).

Segundo Larcher (2004 apud Silva Júnior et al., 2012), a luz é um fator fundamental para as plantas no processo de regulação do crescimento e desenvolvimento vegetativo e reprodutivo. As respostas morfofisiológicas das plantas não dependem apenas da presença, atenuação ou ausência da luz, mas também da variação em qualidade luminosa.

Foram observadas modificações na anatomia foliar de plantas de Dendranthema grandiflorum submetidas a sombreamento por malhas coloridas, uma vez que a folha é um órgão plástico e sua estrutura interna adaptase às condições externas do ambiente (Braga et al., 2009). Medri \& Perez (1980) verificaram variações foliares na forma, tamanho, espessura, densidade e rusticidade em função da intensidade de luz, provocando modificações hormonais, estruturais e morfológicas em videira. Queiroz-Voltan et al. (2011) constataram maior espessura do limbo e maior desenvolvimento do parênquima paliçádico em condições de maior incidência luminosa. Não foram encontradas citações semelhantes para cana-de-açúcar. De acordo com Silva Júnior et al. (2012), nos ambientes de maior radiação difusa e maior temperatura, esses fatores favoreceram a diferenciação de xilema e floema.

Conhecer a morfologia foliar, as funções dos tecidos vegetais e suas possiveis modificações frente aos danos causados pela presença de plantas invasoras pode ser determinante na tomada de decisão quanto ao manejo adequado a ser empregado, assim como predizer os prejuizos estimados pelo não controle.

Tendo em vista o exposto, o objetivo deste trabalho foi avaliar parâmetros de produção e morfoanatômicos de tecidos foliares da canade-açúcar, em condições de matocompetição.

\section{MATERIAL E MÉTODOS}

O experimento foi conduzido em Dracena, Estado de São Paulo, durante o período compreendido entre os meses de abril e junho de
2010, em casa de vegetação, na Universidade Estadual Paulista Júlio de Mesquita Filho. Foi realizado o plantio de cana-de-açúcar, variedade RB 867515 , em vasos com capacidade volumétrica de $9 \mathrm{dm}^{3}$ e 490,6 $\mathrm{cm}^{2}$ de área, preenchidos com Argissolo proveniente da camada de 0-0,3 m, previamente peneirado e adubado com ureia - 6,13 g por vaso; superfosfato triplo $-8,15 \mathrm{~g}$ por vaso; e cloreto de potássio - 3,74 g por vaso. Cada vaso continha um minitolete previamente selecionado e plantado a $8 \mathrm{~cm}$ de profundidade. Durante o período de condução do experimento, os vasos foram irrigados sempre que necessário, respeitando a capacidade de campo.

$\mathrm{Na}$ mesma ocasião foram plantadas, a $2 \mathrm{~cm}$ de profundidade, sementes de Brachiaria brizantha e Brachiaria decumbens, consideradas como plantas invasoras ou espécies daninhas, de acordo com os respectivos tratamentos, simulando diferentes condições de matocompetição, na fase de estabelecimento da cana-de-açúcar.

Para as condições de baixa ocorrência de matocompetição, foi considerada a presença de três plantas invasoras por vaso, disponibilizando $163,5 \mathrm{~cm}^{2}$ de área para cada delas. Para as condições de média ocorrência de matocompetição, foi considerada a presença de seis plantas invasoras por vaso, disponibilizando $81,7 \mathrm{~cm}^{2}$ de área para cada. Em condições de alta ocorrência de matocompetição, foi considerada a presença de nove plantas invasoras, sendo $54,5 \mathrm{~cm}^{2}$ de área do vaso para cada uma.

Foi utilizado o delineamento inteiramente casualizado, sendo sete tratamentos e cinco repetições, totalizando 35 parcelas ou vasos. Os tratamentos variaram de acordo com o número de sementes de Brachiaria brizantha e Brachiaria decumbens, sendo: T1 - ausência de matocompetição; T2 - baixa ocorrência de matocompetição com Brachiaria brizantha; T3 - média ocorrência de matocompetição com Brachiaria brizantha; T4 - alta ocorrência de matocompetição com Brachiaria brizantha; T5 - baixa ocorrência de matocompetição com Brachiaria decumbens; T6 - média ocorrência de matocompetição com Brachiaria decumbens; e T7 - alta ocorrência de matocompetição com Brachiaria decumbens. 
Para avaliação dos efeitos da matocompetição, após 60 dias do plantio da cana-deaçúcar e das espécies Brachiaria brizantha e Brachiaria decumbens, consideradas invasoras, foi avaliada a massa, ou seja, o peso da matéria seca total das plantas. Com relação aos parâmetros morfoanatômicos da cana-deaçúcar, em cada parcela foram retirados três fragmentos foliares para confecção de 105 lâminas histológicas disponíveis para análise. Cada fragmento continha aproximadamente $5 \mathrm{~cm}$, retirado da porção mediana da primeira folha completamente expandida, a partir do ápice da planta. Os fragmentos foliares foram fixados em solução F.A.A.50 (formaldeído $37 \%$, ácido acético glacial e etanol $50 \%$ na proporção de 1,0:1,0:18,0 - V/V). Após 24 horas, foram lavados em etanol $50 \%$ e depois armazenados em etanol $70 \%$ até a data de realização das análises segundo Kraus \& Arduim (1997). Todos os fragmentos de folhas receberam os procedimentos pertinentes à desidratação, diafanização, inclusão e emblocagem. Com auxílio de um micrótomo de mesa da marca Leica, contendo lâminas de aço, foram realizadas secções transversais de $8 \mu \mathrm{m}$ nos fragmentos foliares que continham a nervura central. Os fragmentos sofreram processo de clarificação com hipoclorito de sódio $50 \%$. Todas as secções foram coradas com safranina $1 \%$ e azul de anilina $1,0 \%$ e montadas em lâmina e lamínula com adesivo Entellan.

As lâminas foram observadas em microscópio óptico da marca Leica, contendo uma câmera acoplada para realização das fotografias dos cortes. As fotos foram utilizadas para as medições dos parâmetros anatômicos, pelo programa de análise de imagem QWin, calibrado com régua microscópica nos mesmos aumentos das fotografias, segundo metodologia descrita por Pereira et al. (2008). Foram mensurados, segundo Carlquist (1975), os parâmetros quantitativos dos tecidos: espessura da epiderme da face superior ou adaxial (EAD); espessura da epiderme da face inferior ou abaxial (EAB); espessura do mesofilo (MF); espessura do limbo (EL); diâmetro dos vasos xilemáticos (DX); e diâmetro dos vasos floemáticos (DF), conforme ilustrado na Figura 9.

As variáveis foram submetidas à análise de variância pelo teste $\mathrm{F}(\mathrm{p}<0,05)$. Nos casos em que houve diferença significativa entre os tratamentos, foram realizadas análises de regressão, sendo utilizado o programa Assistat 7.6 Beta.

\section{RESULTADOS E DISCUSSÃO}

Foi constatado que os valores para peso da matéria seca total da cana-de-açúcar foram significativamente menores do que os apresentados pelas espécies Brachiaria brizantha e Brachiaria decumbens, conforme demonstrado nas Figuras 1 e 2. Esse resultado sugere um sombreamento competitivo entre as espécies vegetais, que pode provocar a redução da capacidade e eficiência fotossintética da canade-açúcar. Conforme explicitado por Lorenzi (1988) e Harper (1977), a presença de plantas daninhas nas áreas de cultivo afeta negativamente a produtividade dos canaviais, devido à competição pelos fatores do meio, principalmente por água, espaço, nutrientes e luminosidade.

Os resultados exibidos para a espessura das epidermes adaxial e abaxial da folha da cana-de-açúcar apresentaram redução, em função da matocompetição com Brachiaria brizantha ou Brachiaria decumbens, conforme demonstrado nas Figuras 3 e 4 . Os danos provocados pela matocompetição fizeram com que as epidermes adaxial e abaxial das folhas da cana-de-açúcar se apresentassem mais delgadas, quando comparadas com as de plantas sem a presença de espécies invasoras.

As observações demonstram que estresses de qualquer natureza, sejam de origem biótica ou abiótica, podem afetar a espessura epidérmica foliar. Como as funções principais desse tecido são a proteção da superficie vegetal e o controle das trocas gasosas, inclusive de vapor d'água, plantas que apresentam epidermes mais espessas podem melhor proteger o mesofilo contra as diversas injúrias (Castro et al., 2009). Segundo esses autores, uma outra importante função da epiderme é evitar a predação por insetos, caracóis e outros animais. Essa propriedade pode ser mais acentuada em razão da incorporação de cristais de sílica na parede celular vegetal, que confere maior resistência e abrasão, dificultando a ingestão pelos animais. A diminuição da espessura da epiderme foliar provocada pela 


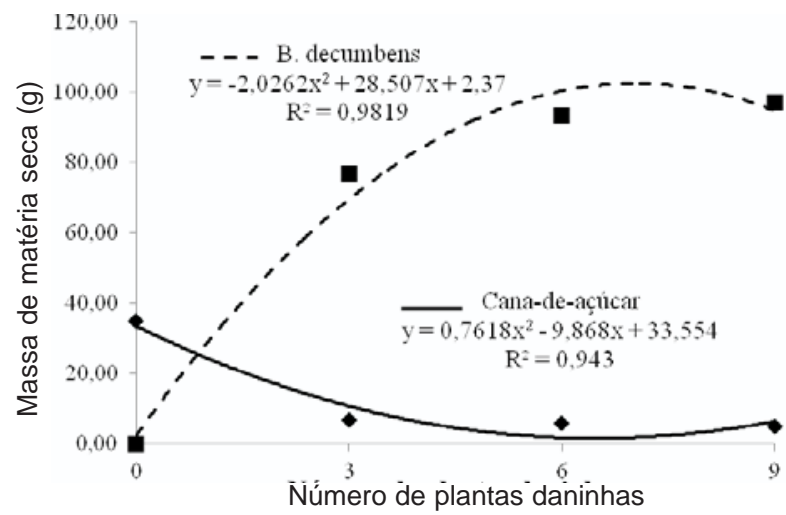

Figura 1 - Peso de matéria seca da parte aérea e raiz da cana-deaçúcar e das plantas invasoras, espécie Brachiaria decumbens, em função da matocompetição. Dracena-SP, 2012.

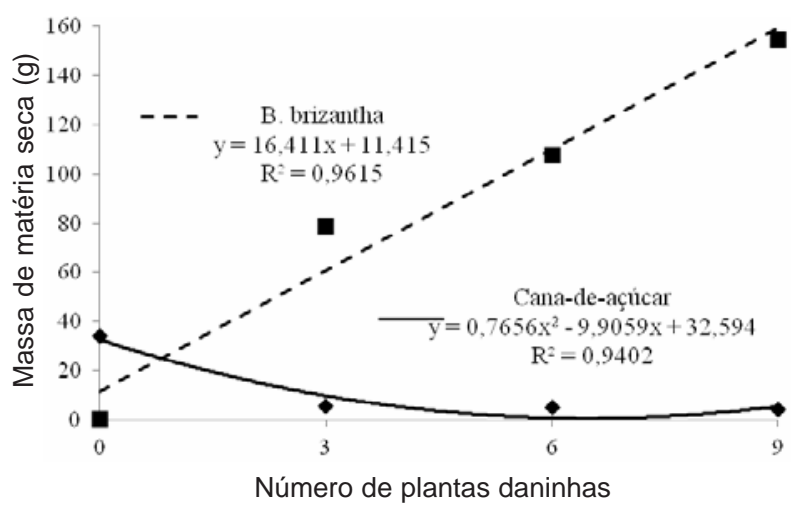

Figura 2 - Peso de matéria seca da parte aérea e raiz da cana-deaçúcar e das plantas invasoras, espécie Brachiaria brizantha, em função da matocompetição. Dracena-SP, 2012.

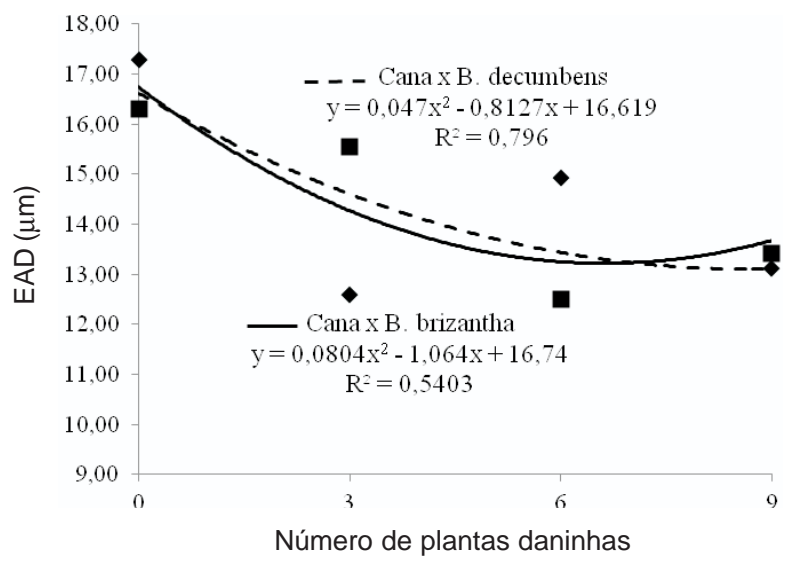

Figura 3 - Espessura da epiderme adaxial (EAD) da cana-deaçúcar, em função da matocompetição com B. brizantha e B. decumbens. Dracena-SP, 2012.

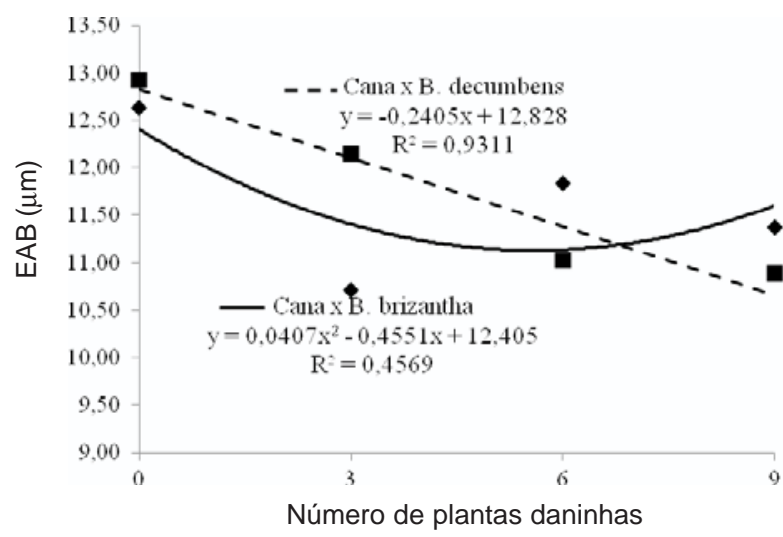

Figura 4 - Espessura da epiderme abaxial (EAB) da cana-deaçúcar, em função da matocompetição com B. brizantha e B. decumbens. Dracena-SP, 2012.

matocompetição conduz a planta a uma condição de fragilidade em relação aos fatores do meio. Outro ponto a ser destacado é a capacidade de reflexão da radiação luminosa que incide sobre as plantas, principalmente aquelas de clima tropical, em função da presença da cutícula, que proporciona aspecto brilhante das folhas, evitando o superaquecimento provocado pela radiação infravermelha.

Resultados semelhantes foram encontrados por Castro et al. (2007) em folhas de quaco, quando em diferentes niveis de sombreamento. Nessas condições, epidermes mais espessas foram observadas em plantas com exposição total à incidência luminosa. Gardoni et al. (2007) verificaram diminuição do tamanho das células epidérmicas abaxiais da Marcetia taxifolia devido à deficiência hídrica.

De maneira geral, com o aumento dos níveis de infestação de plantas invasoras, houve diminuição da espessura do mesofilo e do limbo da cana-de-açúcar, conforme observado nas Figuras 5 e 6 . Para as duas características, a matocompetição da cana-de-açúcar com a espécie Brachiaria decumbens foi mais acentuada. Entre os diversos tecidos que compõem o mesofilo está o parênquima clorofiliano, que contém células com quantidade abundante de cloroplastos e espaços intercelulares, responsável pela realização da fotossíntese, e que conta com a presença de substâncias nutritivas, as quais permitem o metabolismo vital às plantas. Alterações na espessura do mesofilo podem influenciar na quantidade ou 


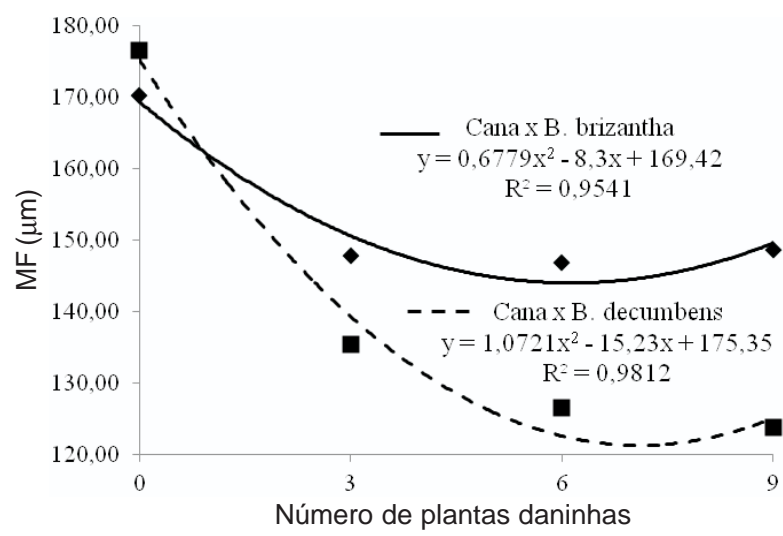

Figura 5 - Espessura do mesofilo (MF) da cana-de-açúcar, em função da matocompetição com $B$. brizantha e $B$. decumbens. Dracena-SP, 2012

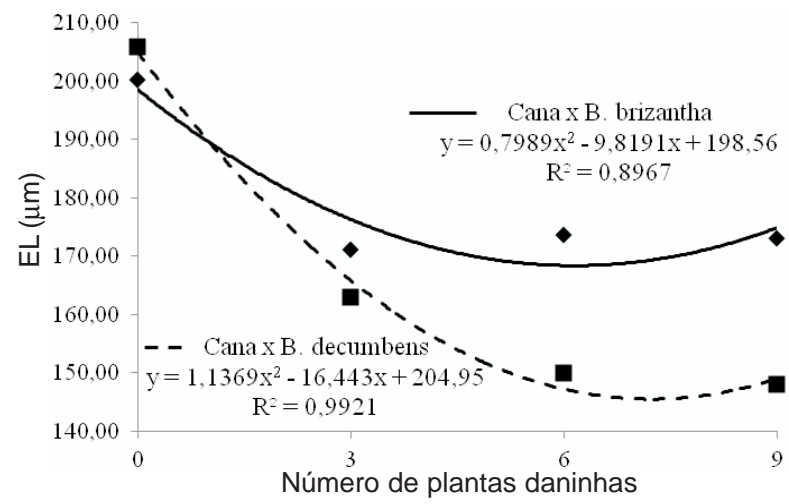

Figura 6 - Espessura do limbo (EL) da cana-de-açúcar, em função da matocompetição com B. brizantha e B. decumbens. Dracena-SP, 2012.

qualidade das substâncias produzidas, interferindo diretamente na produtividade das culturas (Castro et al., 2009). Queiroz-Voltan et al. (2011) constataram que variações no mesofilo podem interferir potencialmente na capacidade fotossintética e na produtividade dos frutos de videira. É interessante destacar que plantas sombreadas investem relativamente maior proporção de fotoassimilados no aumento da área foliar, a fim de maximizar a captação da luz disponivel, produzindo folhas mais finas e com menor densidade de massa (Lambers et al., 1998).

De acordo com Meziane \& Shipley (1999), as modificações na espessura foliar são decorrentes das alterações na espessura da epiderme, no volume das células mesofílicas, no número de camadas de mesofilo, na quantidade de espaços intercelulares no mesofilo, na espessura das nervuras ou espessura da parede celular.

A matocompetição também provocou a diminuição do diâmetro dos vasos condutores de seiva da cana-de-açúcar, segundo demonstrado nas Figuras 7 e 8 . As alterações nos vasos condutores, provavelmente, ocorreram em consequência dos prejuízos provocados pela matocompetição, em função da menor disponibilidade de água, nutrientes, entre outros. O menor calibre dos vasos condutores pode influenciar de forma direta e significativa a fotossintese e, consequentemente, o crescimento e desenvolvimento dos órgãos vegetais.

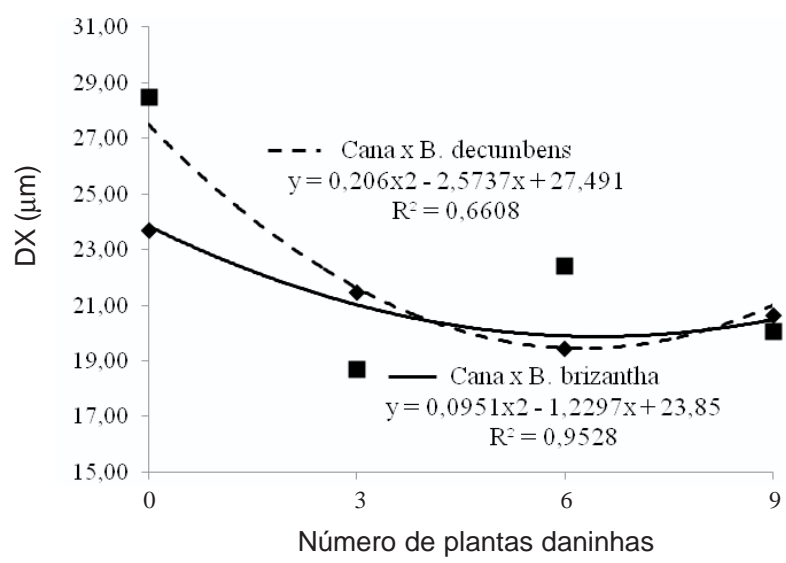

Figura 7 - Diâmetro dos vasos xilemáticos (DX) da cana-deaçúcar, em função da matocompetição com B. brizantha e B. decumbens. Dracena-SP, 2012.

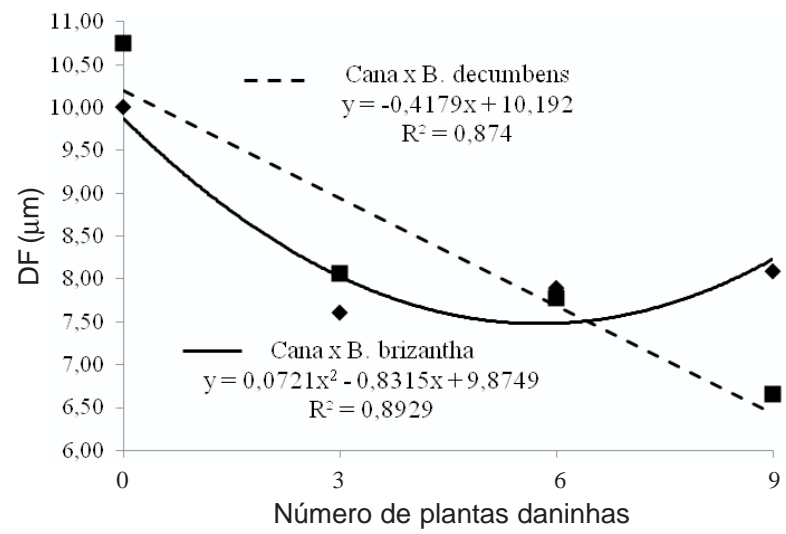

Figura 8 - Diâmetro dos vasos floemáticos (DF) da cana-deaçúcar, em função da matocompetição com $B$. brizantha e B. decumbens. Dracena-SP, 2012. 
A redução do diâmetro dos vasos do xilema e floema, em decorrência da matocompetição, contraria os resultados encontrados por Alves \& Angyalossy-Alfonso (2000). Esses autores concluíram que os fatores ambientais alteram as dimensões e o arranjo dos elementos vasculares de forma positiva, na tentativa de garantir aumento na segurança do transporte, quando a planta está sujeita a algum tipo de estresse.

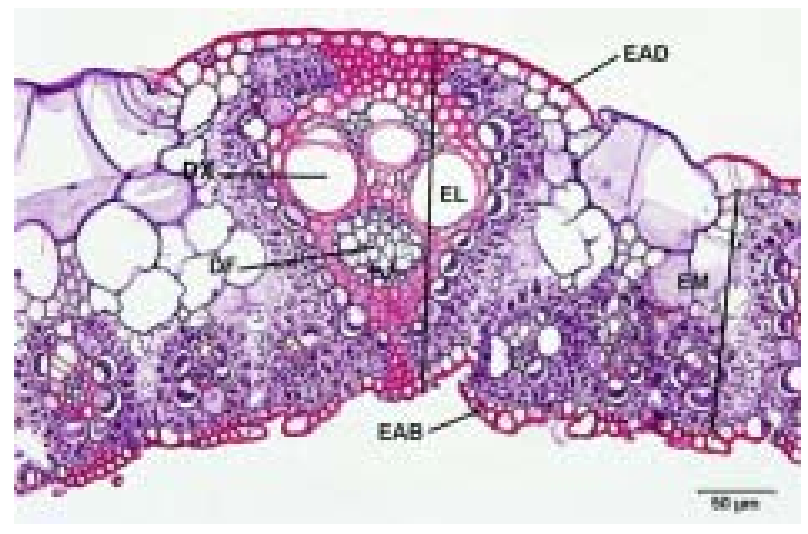

Figura 9 - Parâmetros avaliados nas secções transversais de folhas de cana-de-açúcar em matocompetição com $B$. brizantha e $B$. decumbens: EAD - espessura da epiderme adaxial; EAB - espessura da epiderme abaxial; MF espessura do mesofilo; EL - espessura do limbo; DX diâmetro dos vasos xilemáticos; DF - diâmetro dos vasos floemáticos. Dracena-SP, 2012.

Cunha et al. (2008) verificaram aumento da lignificação e diminuição do diâmetro do tecido vascular devido à aplicação de cádmio e zinco. Esses autores estabelecem uma relação direta entre a modificação das características do meio e as alterações anatômicas das células dos tecidos vegetais.

A matocompetição das espécies Brachiaria brizantha e Brachiaria decumbens, consideradas como invasoras, provocou redução das características morfoanatômicas e de produção da cana-de-açúcar. De maneira geral, Brachiaria decumbens foi a espécie que mais influenciou negativamente a espessura foliar da cana-de-açúcar.

\section{LITERATURA CITADA}

ALVES, E. S.; ANGYALOSSY-ALFONSO, V. Ecological trends in the wood of some Brazilian species 1: growth rings and vessels. IAWA J., v. 21, p. 3-30, 2000.
BLANCO, H. G. A importância dos estudos ecológicos nos programas de controle de plantas daninhas. Biológico, v. 38, n. 10, p. 343-350, 1972.

BRAGA, F. T. et al. Qualidade de luz no cultivo in vitro de Dendranthema grandiflorum cv. Rage: características morfofisiológicas. Ci. Agrotecnol., v. 33, n. 2, p. 502-508, 2009. Disponível em: <http://www.scielo.br/s c i e l o . p h p ? script=s ci_artte xt \& pid = S 1413 70542009000200022>. Acesso em: 12 mar. 2011. Doi: 10.1590/S1413-70542009000200022.

CARLQUIST, S. Ecological estrategies of xylem evolution. Berkeley: University of California Press, 1975, 259 p.

CASTRO, E. M. de et al. Histologia vegetal: estrutura e função de órgãos vegetativos. Lavras: Universidade Federal de Lavras, 2009. 234 p.

CASTRO, E. M. et al. Adaptações anatômicas de folhas de Mikania glomerata Sprengel (Asteraceae), em três regiões distintas da planta, em diferentes níveis de sombreamento. R. Bras. Plantas Medic., v. 9, n. 2, p. 8-16, 2007.

CORREIA, N. M.; KRONKA JR., B. Controle químico de plantas dos gêneros Ipomoea e Merremia em cana-soca. Planta Daninha, v. 28, p. 1143-1152, 2010.

(Número Especial)

CUNHA, K. P. V. et al. Disponibilidade, acúmulo e toxidez de cádmio e zinco em milho cultivado em solo contaminado. R. Bras. Ci. Solo, v. 32, n. 3, p. 1319-1328, 2008.

GARDONI, L. C. P. et al. Morfologia e anatomia foliar de três morfotipos de Marcetia taxifolia (A.St.-Hil) DC. (Melastomataceae) na Serra do Cipó, MG. R. Bras. Bot., v. 30, n. 3, p. 487-500, 2007.

HARPER, J. L. The population biology of plants. London: Academic Press, 1977. 892 p.

INSTITUTO BRASILEIRO DE GEOGRAFIA E ESTATÍSTICA - IBGE. Em 2012, IBGE prevê safra 0,3\% maior que em 2011. Disponível em: <http:// www.ibge.gov.br/home/presidencia/noticias/ noticia_visualiza.php?id_noticia=2065\&id_pagina=1>. Acesso em: 15 jun. 2012.

KRAUS, J. E.; ARDUIN, M. Manual básico de métodos em morfologia vegetal. Seropédia: EDUR, 1997. $198 \mathrm{p}$.

KUVA, M. A. et al. A períodos de interferência das plantas daninhas na cultura da cana-de-açúcar. iii - capimbraquiária (Brachiaria decumbens) e capim-colonião (Panicum maximum). Planta Daninha, v. 21, n. 1, p. 37-44, 2003.

Planta Daninha, Viçosa-MG, v. 31, n. 4, p. 777-784, 2013 
LAMBERS, H. et al. Plant physiological ecology. New York: Springer, 1998. $540 \mathrm{p}$.

LORENZI, H. Plantas daninhas e seu controle na cultura da cana-de-açúcar. In: SEMINÁRIO DE TECNOLOGIA AGRONÔMICA, 4., 1988, Piracicaba. Anais... São Paulo: COOPERSUCAR, 1988. p. 281-301.

MEDRI, M. E.; PEREZ, E. L. Aspectos da anatomia ecológica de folhas de Hevea brasiliensis Mell. Arg. Acta Amaz., v. 10, n. 3, p. 463-493, 1980.

MEZIANE, D.; SHIPLEY, B. Interacting determinants of specific leaf área in 22 herbaceous species: effects of irradiance and nutrient availability. Plant Cell Environ., v. 22, n. 5, p. 447-459, 1999.

PEREIRA, F. J. et al. Evolução da anatomia radicular do milho 'Saracura' em ciclos de seleção sucessivos. Pesq. Agropec. Bras., v. 43, n. 12, p. 1649-1656, 2008.
PITELLI, R. A. Interferência de plantas daninhas em culturas agrícolas. Inf. Agropec., v. 120, n. 11, p. 16-27, 1985.

QUEIROZ-VOLTAN, R. B. et al. Variações na anatomia foliar de videira Niagara em diferentes sistemas de condução. Bragantia, v. 70, n. 3, p. 488-493, 2011.

SANT'ANNA-SANTOS, B. F. et al. Danos morfoanatômicos causados pelo glyphosate em folhas de Eucalyptus grandis W. Hill ex Maiden (Myrtaceae). In: SIMPÓSIO

INTERNACIONAL SOBRE GLYPHOSATE, 1., 2007.

Anais... [S.l.: s.n.], 2007.

SILVA JÚNIOR, J. M. et al. Variações anatômicas de Laelia purpurata var. cárnea cultivada in vitro sob diferentes intensidades e qualidade espectral de luz. Ci. Rural, v. 42, n. 3, p. 480-486, 2012. 